\title{
New type of encephalomyelitis responsive to trimethoprim/sulfamethoxazole treatment in Japan
}

\section{OPEN}

Yusuke Sakiyama, MD, PhD*

Naoaki Kanda, MD* Yujiro Higuchi, MD

Michiyoshi Yoshimura, MD

Hiroyuki Wakaguri, PhD Yoshiharu Takata, MD

Osamu Watanabe, MD, $\mathrm{PhD}$

Junhui Yuan, MD, PhD

Yuichi Tashiro, MD

Ryuji Saigo, MD

Satoshi Nozuma, MD

Akiko Yoshimura, BS

Shiho Arishima, DVM

Kenichi Ikeda, MD

Kazuya Shinohara, MD

Hitoshi Arata, MD, PhD

Kumiko Michizono, MD, $\mathrm{PhD}$

Keiko Higashi, MD

Akihiro Hashiguchi, MD

Yuji Okamoto, MD, PhD

Ryuki Hirano, MD, PhD

Tadafumi Shiraishi, MD

Eiji Matsuura, MD, PhD

Ryuichi Okubo, MD

Itsuro Higuchi, MD

Masamichi Goto, MD

Hirofumi Hirano, MD,

$\mathrm{PhD}$

Akira Sano, MD, PhD

Takuya Iwasaki, MD

Fumihiko Matsuda, PhD

Shuji Izumo, MD

Hiroshi Takashima, MD, $\mathrm{PhD}$

Correspondence to

Dr. Takashima:

thiroshi@m3.kufm.kagoshima-u. ac.jp

Supplemental data at Neurology.org/nn

\section{ABSTRACT}

Objective: To determine the causative pathogen and investigate the effective treatment of a new type of encephalomyelitis with an unknown pathogen in Japan and report the preliminary ultrastructural and genomic characterization of the causative agent.

Methods: From 2005 to 2012, we treated 4 Japanese patients with geographic clustering and comparable clinical features, serum/CSF cytology, and radiologic findings. Brain biopsy was conducted in all patients to analyze neuropathologic changes by histology, and electron microscopy was applied to reveal the features of the putative pathogen. Genomic DNA was obtained from the affected brain tissues and CSF, and an unbiased high-throughput sequencing approach was used to screen for specific genomic sequences indicative of the pathogen origin.

Results: All patients exhibited progressive dementia with involuntary tongue movements. Cytologic examination of CSF revealed elevated mononuclear cells. Abnormal MRI signals were observed in temporal lobes, subcortical white matter, and spinal cord. Biopsied brain tissue exhibited aggregated periodic acid-Schiff-positive macrophages and 2-7 $\mu \mathrm{m}$ diameter round/oval bodies without nuclei or cell walls scattered around the vessels. Unbiased high-throughput sequencing identified more than 100 archaea-specific DNA fragments. All patients were responsive to trimethoprim/sulfamethoxazole (TMP-SMX) plus corticosteroid therapy.

Conclusions: We report 4 cases of encephalomyelitis due to an unknown pathogen. On the basis of ultrastructural and genomic studies, we propose a new disease entity resulting from a causative pathogen having archaeal features. TMP-SMX therapy was effective against this new type of encephalomyelitis. Neurol Neuroimmunol Neuroinflamm 2015;2:e143; doi: 10.1212/ NXI.0000000000000143

\section{GLOSSARY}

CXCL13 = C-X-C motif chemokine 13; FLAIR = fluid-attenuated inversion recovery; H\&E = hematoxylin \& eosin; LMD = laser microdissection; $\mathbf{m R N A}$ = messenger RNA; OCB = oligoclonal lgG band; PAS = periodic acid-Schiff; rRNA = ribosomal RNA; TMP-SMX = trimethoprim/sulfamethoxazole; $\mathbf{W B C}=$ white blood cell.

Numerous neurodegenerative diseases, infections, metabolic anomalies, and toxins can result in progressive dementia. ${ }^{1}$ Many cases are reversible if treated in the early stages; thus, timely diagnosis by the identification of the causative agent based on extensive examination is required. Infectious encephalitis or encephalomyelitis is an important cause of treatable dementia and comprises a variety of diseases, including herpes simplex virus 1 and 2 infection, cytomegalovirus infection, Epstein-Barr viral infection, HIV infection, neurosyphilis, mycobacterial infection, Whipple disease, neuroborreliosis, Bartonella henselae infection, cryptococcal meningitis, malaria, and trypanosomiasis. ${ }^{2}$ These diseases and infections are usually accompanied by

*These authors contributed equally to this manuscript.

From the Department of Neurology and Geriatrics (Y.S., N.K., Y.H., M.Y., Y. Takata, O.W., J.Y., Y. Tashiro, R.S., S.N., A.Y., K.I., K.S., H.A., K.M., K.H., A.H., Y.O., R.H., T.S., E.M., R.O., I.H., T.I., H.T.), Center for Chronic Viral Diseases (S.A., S.I.), Department of Neurosurgery (H.H.), and Department of Psychiatry (A.S.), Kagoshima University Graduate School of Medical and Dental Sciences, Kagoshima, Japan; Center for Genomic Medicine (H.W., F.M.), Kyoto University Graduate School of Medicine, Kyoto, Japan; Department of Neurology (Y. Tashiro, R.S.), Fujimoto Hayasuzu Hospital, Miyazaki, Japan; and National Sanatorium Hoshizuka Keiaien (M.G.), Kagoshima, Japan.

Funding information and disclosures are provided at the end of the article. Go to Neurology.org/nn for full disclosure forms. The Article Processing Charge was paid by the authors.

This is an open access article distributed under the terms of the Creative Commons Attribution-NonCommercial-NoDerivatives License 4.0 (CC BY-NC-ND), which permits downloading and sharing the work provided it is properly cited. The work cannot be changed in any way or used commercially. 
other hallmarks of infection. Furthermore, geographical clustering of patients is a strongly suggestive factor for infectious diseases.

In 2005, we encountered a patient with severe early-onset dementia. Histopathology of biopsied brain tissue revealed encephalitis. The putative pathogen was cell wall deficient and exhibited several unreported features. In the following 7 years, we treated 3 additional patients presenting with similar clinical symptoms and pathologic findings. All patients inhabited towns located on a peninsula of Kyushu Island, Japan. Here we describe the clinical, pathologic, and radiologic findings of this disease and report results of genomic screening for preliminary identification of the causative pathogen.

METHODS Patient 1. The first patient presenting with this unique form of encephalomyelitis was a 47-year-old man from a fishing town on Kyushu Island. Three months before admission, he started eating excessively. His speech and daily activities decreased for a few weeks, accompanied by memory disturbance and disorientation. Two physicians made an initial diagnosis of Alzheimer disease. No abnormalities were observed on blood analyses or MRI during the first 3 months after onset; however, from the fourth month, elevated CSF cell count was observed and fluid-attenuated inversion recovery (FLAIR) MRI revealed high signal intensity regions in the dorsal pons, bilateral insular cortex, and subcortical temporal region (figure 1, A-C). Neurologic examination revealed severe disorientation, loss of calculation, and memory

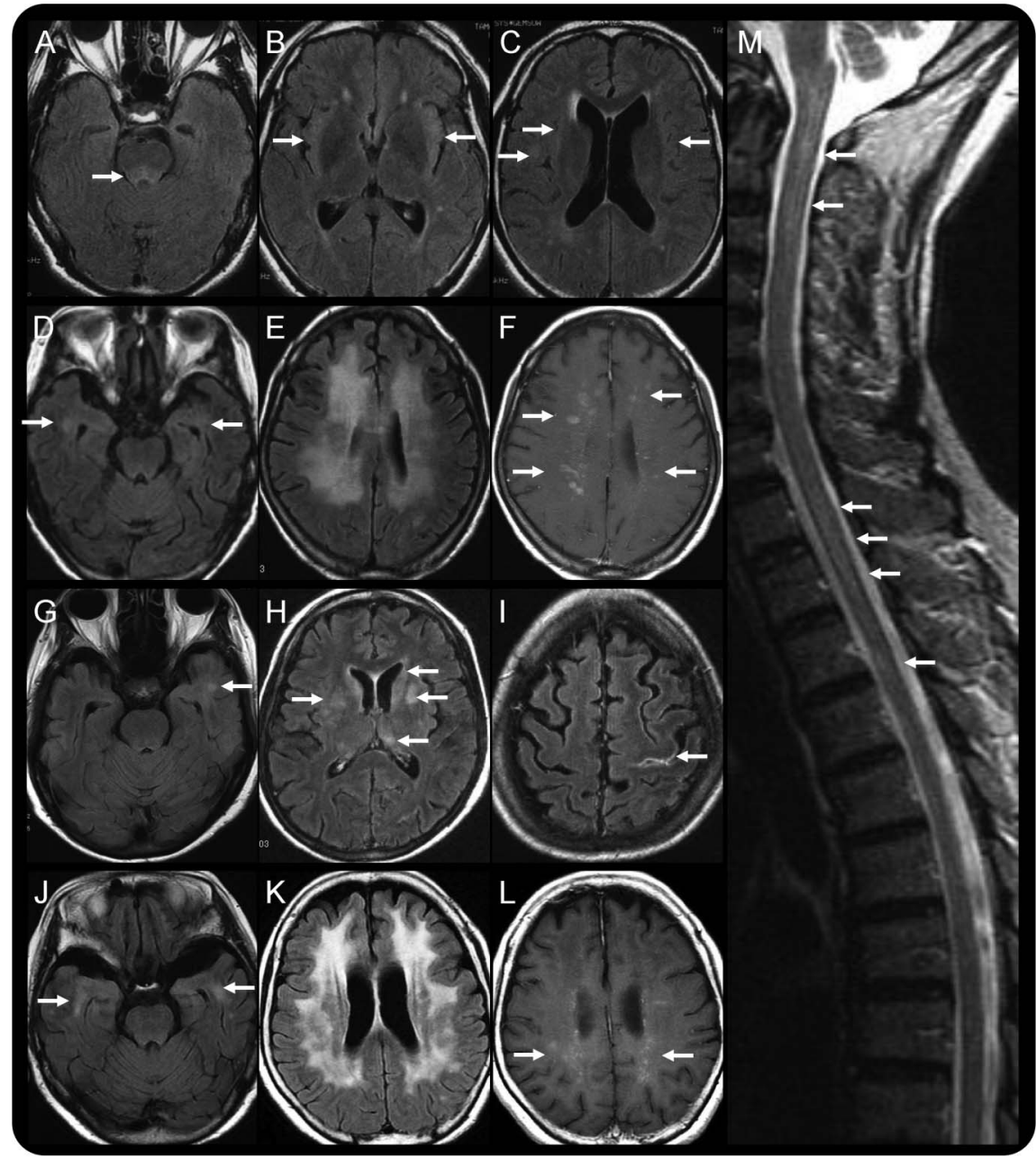

(A-C) patient 1; (D-F) patient 2; (G-I) patient 3; (J-L) patient 4; and (M) patient 2. Brain fluid-attenuated inversion recovery (FLAIR) MRI performed on admission (A-C) revealed abnormally high intensity at the dorsal pons, bilateral insular cortex, and subcortical region in patient 1 . According to FLAIR MRI, patient 2 and patient 4 had similar brain lesions, including abnormalities around the inferior horn of the lateral ventricle $(D, J)$ and diffuse high intensity in the deep white matter of the frontotemporoparietal regions $(E, K)$. These lesions are mainly confined to the white matter, as revealed by the relative sparing of the cortex, and are enhanced by gadolinium administration in T1-weighted MRI (F, L). In contrast, FLAIR MRI of patient 3 revealed patchy lesions in the subcortical area of the left temporal lobe $(\mathrm{G})$ and in the basal ganglion $(\mathrm{H})$. Contrastenhanced FLAIR MRI revealed hyperintense lesions along the left central sulcus (I). Sagittal T2-weighted images depict an inhomogeneously hyperintense spinal cord, stretching from the cervico-occipital junction to the thoracic cord region (M). 
disturbance. Dystonic tongue movements and intermittent myoclonic movements of the limbs were also observed; however, ambulation was normal. Physical examination revealed hyperreflexia in extremities, a positive sucking reflex, and positive Babinski and Chaddock signs.

Hematologic data were normal, whereas white blood cell (WBC) count $(27$ cells $/ \mu \mathrm{L})$ and protein level $(78 \mathrm{mg} / \mathrm{dL})$ were elevated in CSF, strongly suggesting an infection or autoimmune disease; however, tests for serum autoantibodies and known infectious agents associated with encephalomyelitis were all negative (table e-1 at Neurology.org/nn).

The patient was initially administered ceftriaxone, streptomycin, methylprednisolone, and IV immunoglobulin for infectious or autoimmune encephalitis, which slightly improved his symptoms during the first 2 weeks of treatment; however, the recovery ceased thereafter, and brain MRI indicated enlargement of the lesions, particularly in the lower temporal lobes (figure e-1A). Whipple disease was considered as a potential diagnosis, although only a few patients with this disease had been reported in Japan. ${ }^{3-5}$ However, the absence of periodic acid-Schiff (PAS)-positive macrophages in duodenal biopsy argued against Tropheryma whipplei infection. Subsequently brain biopsy was performed and the potential infectious organism was ultrastructurally and genetically characterized.

Electron microscopic analysis of brain biopsy tissue revealed a round- to oval-shaped pathogen. Treatment with high-dose trimethoprim/sulfamethoxazole (TMP-SMX) $(1 \mathrm{~g}$ of TMP-SMX contained $400 \mathrm{mg}$ sulfamethoxazole and 80 $\mathrm{mg}$ trimethoprim, administered at a maximum dose of 12 $\mathrm{g} /$ day) plus prednisolone was started. The patient's symptoms improved daily after treatment initiation. After 3 months the patient's orientation, writing ability, memory, motivation, and calculation ability recovered. In 5 months he was capable of handling most daily activities, and 2 months later he could use the Internet and commence work. Seven years after onset, memory disturbance and disorientation recurred following withdrawal of medication; thus, treatment with TMP-SMX was reinitiated $(8 \mathrm{~g} /$ day $)$ and the patient gradually recovered (figure e-1C). Figure e-2 summarizes the clinical course of this first patient.

Detailed clinical data on patients $2-4$ are described in appendix e-1.

Standard protocol approvals, registrations, and patient consents. All 4 patients with progressive dementia (referred by neurologists) were examined and treated at Kagoshima University Hospital. Relatives of the patients provided written informed consent for study participation. The Institutional Review Board of Kagoshima University approved the study.

Histopathology. Brain biopsies were performed in all 4 patients. Tissue blocks were fixed in $4 \%$ paraformaldehyde in $0.1 \mathrm{M}$ phosphoric acid buffer and embedded in paraffin. Paraffin sections were subsequently stained with hematoxylin and eosin (H\&E), Gram stain, Grocott stain, and PAS. Serial tissue sections were stained with anti-CD4 (Nichirei Corp., Tokyo, Japan), anti-CD8, and anti-CD68 (Dako, Glostrup, Denmark). Smaller specimens were fixed in $3 \%$ glutaraldehyde in $0.1 \mathrm{M}$ phosphoric acid buffer and embedded in Epon 812.

Amplification of 16S/18S ribosomal RNA. DNA samples were isolated from the CSF of all patients and from the biopsied brain samples of patients 3 and 4 . Universal primer sets were designed on the basis of previous reports targeting 16S/18S ribosomal RNA (rRNA) from bacteria, fungi, and archaea (table e-2). PCR was performed following standard protocols using KOD-Plus-Neo (Toyobo, Osaka, Japan).

Unbiased high-throughput sequencing. The pathogens found in brain tissue sections of patients 3 and 4 by PAS staining were isolated using a laser microdissection (LMD) system (Leica Microsystems, Wetzlar, Germany). Brain tissues obtained from patients 1 and 2 were excluded from this genetic analysis because in these initial cases no special measures were taken to avoid microbial contamination during specimen handling. In addition, 3 biopsied brain samples, 1 each of papillary meningioma, intravascular lymphomatosis, and glioblastoma, were used as controls. Genomic DNA was extracted from the CSF and LMD samples using a DNA blood and tissue extraction kit (QIAGEN, Tokyo, Japan). Unbiased high-throughput genomic sequencing was performed using a next-generation sequencing system (MiSeq, NextraXT prep kit, Illumina, San Diego, CA) and a paired-end sequencing approach starting with $1 \mathrm{ng}$ genomic DNA. A higher-quality read was obtained by trimming the $3^{\prime}$ end when the average quality value was lower than 20. For identification of nonhuman DNA, the CLC Genomics Workbench (CLC bio, Aarhus, Denmark) was used to search a human genome database (UCSC: hg19) and a human messenger RNA database (RefSeq release 54) and eliminate most human sequences. The remaining unmapped reads were subsequently analyzed by Nucleotide BLAST against the database (GenBank Release 191) from the National Center for Biotechnology Information (http://www. ncbi.nlm.nih.gov/genbank/), with a cutoff E-value of $<1 \mathrm{e}^{\sim 20}$ and hit length of $>80$ bases.

Pathogen-specific primer design and nested PCR. To validate the existence of pathogen DNA detected by unbiased highthroughput sequencing, oligonucleotide primers were designed targeting the sequenced fragments, and nested PCR was conducted using DNA obtained by LMD from patient 3 .

RESULTS Patient characteristics. The onset age of the 4 patients ranged from 47 to 70 years. At onset, the disease was characterized by dementia and involuntary tongue movement. Slowly progressive dementia with motor disturbances emerged within 1 year of onset. Patients exhibited varied clinical phenotypes, including pyramidal signs, parkinsonism, and cerebellar ataxia. On presentation at our institution, all patients exhibited moderate to severe dementia according to the revised Hasegawa Dementia Scale and the Mini-Mental State Examination. ${ }^{6}$ In addition, all patients exhibited pleocytosis (7-64 cells/ $\mu \mathrm{L}$, predominantly mononuclear cells) and elevated protein in the CSF. The CSF levels of C-X-C motif chemokine 13 (CXCL13) were $>500$ $\mathrm{pg} / \mathrm{mL}$ (normal: undetectable) in all patients prior to TMP-SMX administration according to ELISA (R\&D Systems, Abingdon, UK). After administration of TMP-SMX and corticosteroid combination therapy, CSF CXCL13 decreased to $466 \mathrm{pg} / \mathrm{mL}$ in patient $1,211 \mathrm{pg} / \mathrm{mL}$ in patient 2 , $30.7 \mathrm{pg} / \mathrm{mL}$ in patient 3, and $22.2 \mathrm{pg} / \mathrm{mL}$ in patient 4. Clinical histories, physical examination results, and laboratory test results for all 4 patients are summarized in table 1. 
Table $1 \quad$ Initial evaluation of 4 patients with progressive dementia

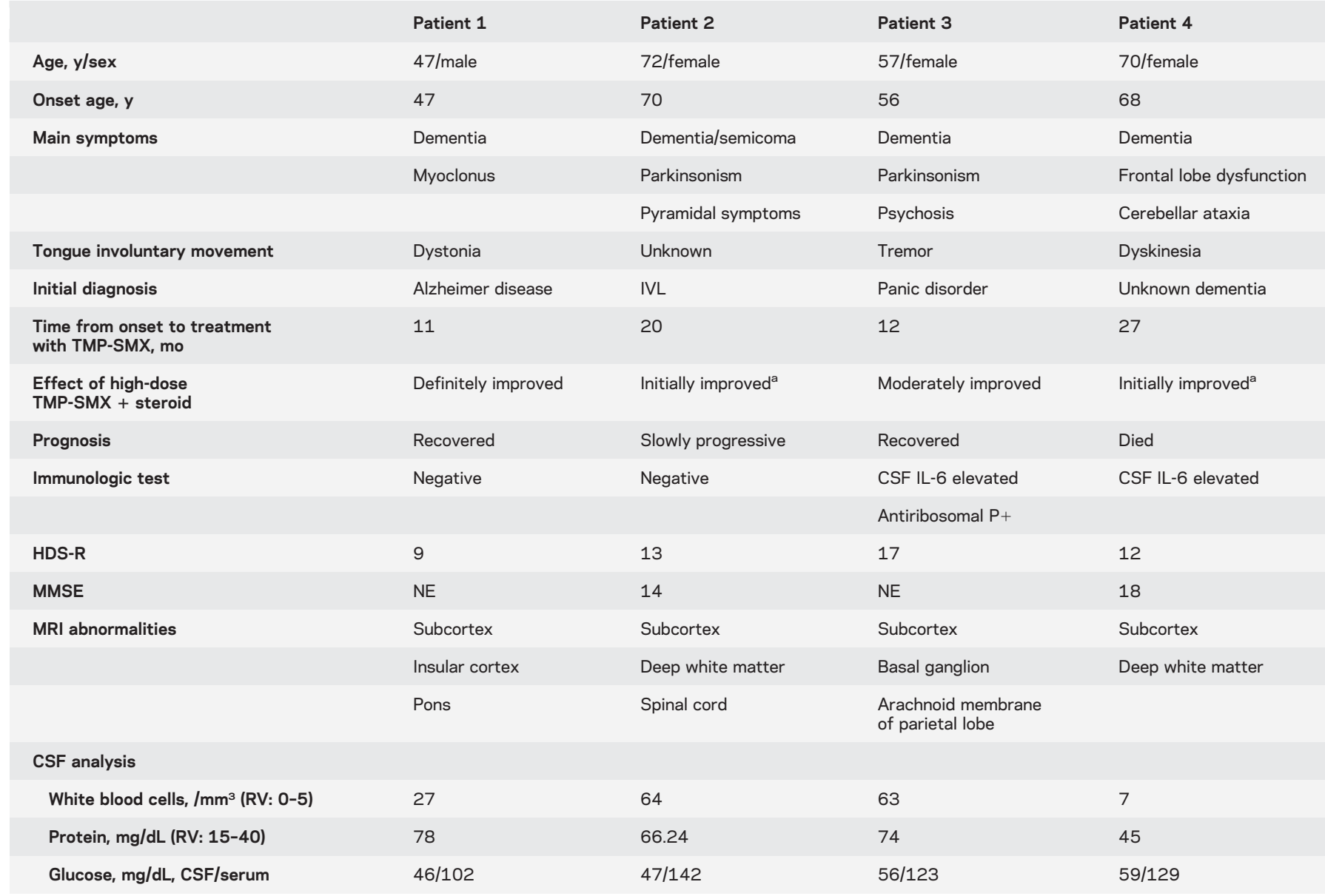

Abbreviations: IL = interleukin; IVL = intravascular lymphoma; HDS-R = Revised Hasegawa Dementia Scale (max score 30); MMSE = Mini-Mental State Examination (max score 30); NE = not examined; RV = reference value; TMP-SMX = trimethoprim/sulfamethoxazole.

${ }^{\text {a }}$ Treatment was not maintained because of liver failure induced by high-dose TMP-SMX.

All patients exhibited hypointensities on FLAIR images, and the lesions were slightly enhanced by gadolinium. These lesions were spread throughout the brain but were particularly noticeable in the subcortical white matter of the temporal lobe. The cortex, basal ganglia, brainstem, and spinal cord could be involved at more advanced stages (figure 1). These abnormalities also improved with TMP-SMX and prednisolone combination therapy (figure e-1).

Histopathology. Brain tissue samples from the 4 patients showed comparable histopathologic changes consisting of perivascular spongiosis and infiltration of mononuclear cells (figure 2, E and F). Subcortical changes were more prominent than cortical changes, and there was slight white matter gliosis. No aggregates of foamy macrophages were seen, but microabscess formation was observed in patient 3. Moreover, infiltration of inflammatory cells was observed in the subarachnoid space. No significant necrosis, hemorrhage, neuronophagia, or demyelination was found.

No pathogen was identified in H\&E-stained sections, but PAS staining revealed round- to oval-shaped bodies (2-7 $\mu \mathrm{m}$ in diameter) in the extracellular area and cytoplasm of macrophages infiltrating the perivascular region (figure 2, B, K-M). Part of these structures morphologically resembled Michaelis-Gutmann bodies. These bodies were positive for Grocott stain (figure 2C) but negative for Gram stain and immunostaining against toxoplasma antigen. Electron microscopy revealed that these bodies were anuclear cells of irregular shape and varying size. They lacked a nuclear membrane and cell wall but showed occasional cytoplasmic structures (figure 2, H-J).

Genomic analysis and gene sequence-based analysis using 16S/18S rRNA. No amplicon products of bacterial, fungal, protozoal, or archaeal origin were obtained from CSF or brain tissue DNA using previously described universal primer pairs targeting 16S/18S rRNA.

Pathogen detection by unbiased next-generation sequencing and nested PCR. Among 7,292,715 DNA fragments obtained from patient 3,130 reads showed a striking homology to Halobacteriaceae (domain Archaea) under 

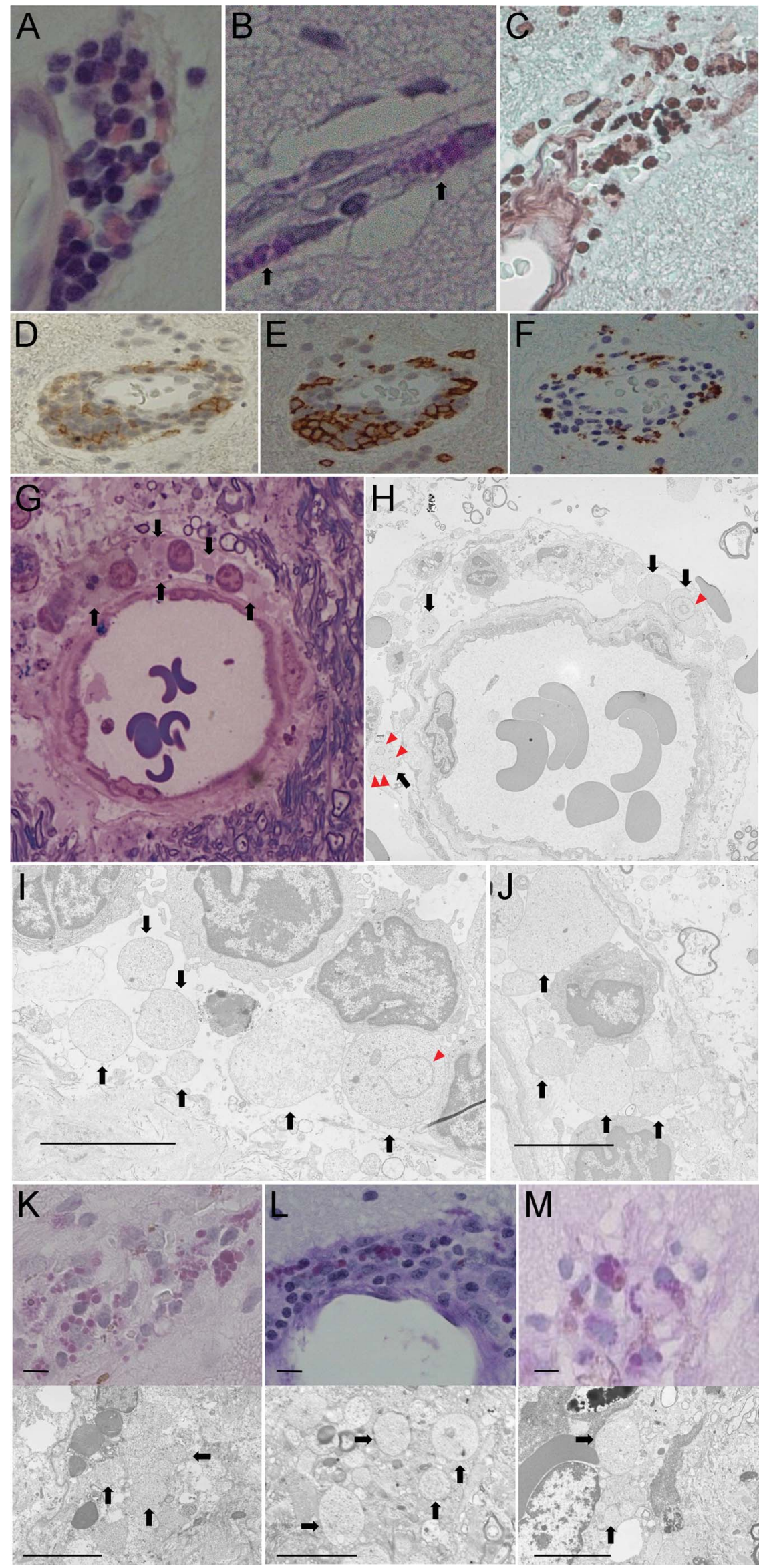
Hematoxylin \& eosin staining (A), periodic acid-Schiff (PAS) staining (B), and Grocott staining (C) of brain biopsy samples show the presence of round pathogens, similar to Michaelis-Gutmann bodies, located mainly around the blood vessels. Some CD4-positive T lymphocytes are also located around the vessels (D). CD8-positive T lymphocytes appear to be the main invasive cells (E), whereas CD68-positive macrophages are only present in patches (F). Toluidine blue and Safranin $\mathrm{O}$ stain of Epon-embedded semithin sections show some pathogens without nuclei around vessels (G). Electron microscopy (H-J) shows an irregular shape of pathogens (diameter 2-7 $\mu \mathrm{m}$ ) without cell walls and nuclei (arrows) but with some membranous structures in the cytoplasm (triangles). Scale bar $=5 \mu \mathrm{m}$. Brain biopsies from patients $2(\mathrm{~K}), 3(\mathrm{~L})$, and $4(\mathrm{M})$ demonstrate a similar histopathology to that of patient 1, with 2-7 $\mu \mathrm{m}$ round PAS-positive pathogens located mainly around the vessels. The agents showed an irregular shape with no detectable cell wall or nucleus under an electron microscope (arrows). Scale bar $=5 \mu \mathrm{m}$.

conditions E-value $<1 \mathrm{e}^{-20}$, hit length $>80$, and identity $>70 \%$ (figure 3 , table e-3). These sequences were not substantially homologous to known bacteria or eukarya sequences (E-value $>1 \mathrm{e}^{3}$ ). Moreover, of 303,698 DNA fragments isolated from patient 4, 126 reads also showed a high degree of homology with Halobacteria, particularly Halorubrum lacusprofundi and Halophilic archaeon (figure 3, table e-3). In contrast, genomic DNA extracted from brain tissues of patients with papillary meningioma (4,760,858 reads), intravascular lymphomatosis $(5,259,934$ reads), or glioblastoma $(5,027,830$ reads) showed no significant homology to known archaeal genomic or mRNA sequences (data not shown).

No amplification of target sequences was obtained from CSF- or LMD-derived DNA of patient 3 and 4 using primers targeting the fragments homologous to Halobacterium (data not shown).
DISCUSSION We report a new type of encephalomyelitis in 4 unrelated Japanese patients. All patients exhibited comparable clinical, radiologic, and histopathologic features, suggesting a shared pathogen. All inhabited a small Japanese island, but no direct person-to-person contact or other mode of transmission was identified; thus, we assumed that other people in this region may be exposed to the causative pathogen, but few are infected.

Progressive disease course, abnormal cytologic results, elevated CXCL13, and radiologic diversity suggested an infectious entity; however, common clinical features of infectious encephalitis, such as fever, increased number of WBCs in peripheral blood count, or elevation of C-reactive protein, were absent. Rather, slow progression and mild pathologic changes in the brain indicated a relatively moderate host immune response, indicative of the weak toxicity or virulence of the pathogen. In addition,

Figure 3 Stepwise strategy of bioinformatic analysis of sequencing results

Patient LMD DNA sample (PAS-positive lesions in biopsied brain tissue)
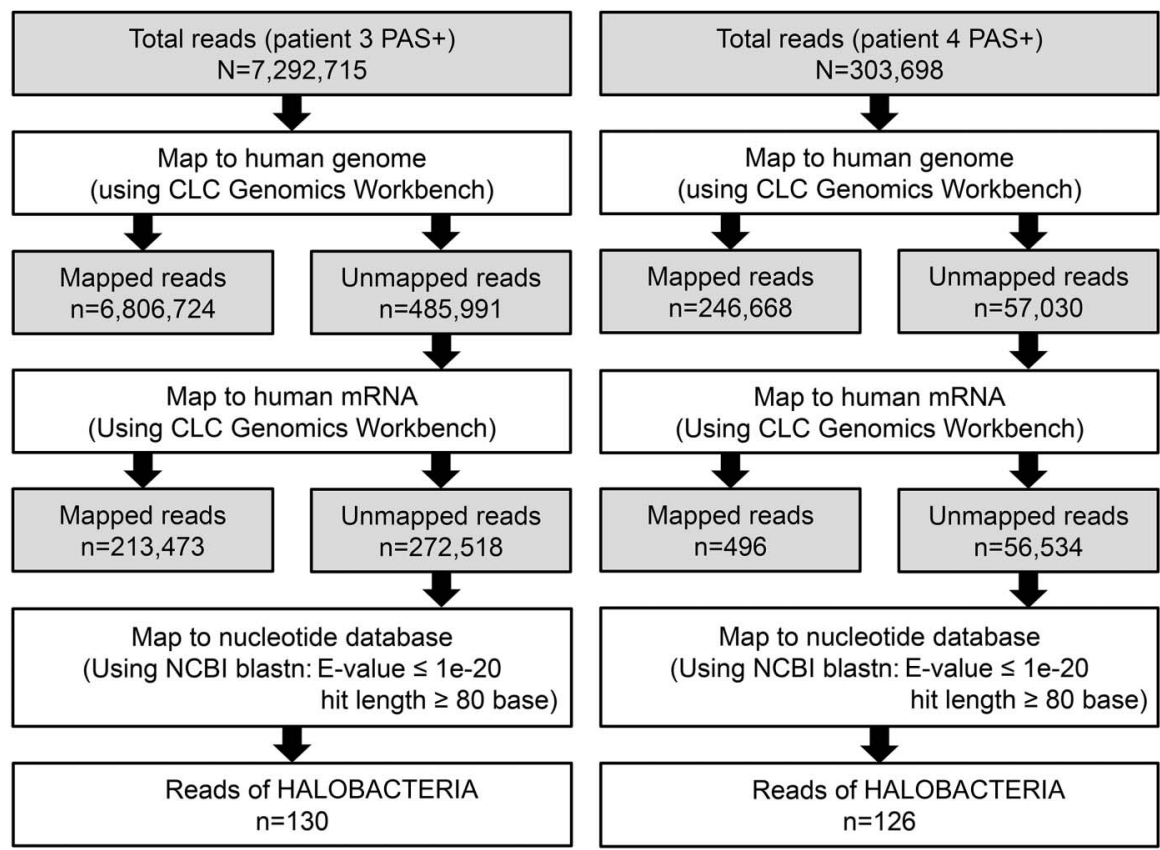

We obtained 7,292,715 and 303,698 DNA sequence reads from the affected brain tissues of patients 3 and 4, respectively. After trimming off low-quality sequence regions, we mapped them to the human genome and messenger RNA (mRNA) reference sequences using CLC Genomics Workbench. The 272,518 reads from patient 3 ( $3.7 \%$ of the total reads) and the 56,534 reads from patient 4 (18.6\% of the total reads) that aligned with neither the human genome nor the mRNA reference sequences were further analyzed using BLASTN against the nucleotide database with a cutoff E-value of $<1 \mathrm{e}^{-20}$. LMD = laser microdissection; NCBI = National Center for Biotechnology Information; PAS = periodic acid-Schiff. 
CSF samples did not show any oligoclonal IgG bands (OCBs) in the patients. The OCB-negative data do not rule out infectious encephalitis because OCBs are detected more frequently in the CSF of patients with herpes simplex encephalitis; however, they are less frequently detected in the CSF of patients with other CNS infections. ${ }^{7}$ The aggregation of inflammatory changes around blood vessels in brain tissue indicated that the pathogen probably invades the CNS through the vasculature.

The common clinical characteristics of these patients (progressive dementia, involuntary tongue movements, CSF abnormalities, and responsiveness to TMP-SMX therapy) are also shared by patients with Whipple disease, a rare systemic infectious disease caused by the bacterium $T$ whipplei. ${ }^{8,9}$ However, facial myorhythmia, a central feature of Whipple disease, was not observed in our patients, and PASpositive macrophages in the duodenum, another defining feature of Whipple disease, were absent. In addition, the ultrastructural features of the putative infectious agent observed in the perivascular spaces and within infiltrating macrophages differed substantially from those of $T$ whipplei (figure 4), and no $T$ whipplei-specific nucleotide sequences were revealed by genomic sequencing.

Brain MRI revealed widely distributed lesions, particularly in the subcortical white matter of the temporal lobes. Lesions in temporal lobe structures or associated efferent and afferent pathways can result in dementia manifesting as memory disturbances and disorientation. Additional spinal cord involvement was observed in patient 2. All these lesions reduced markedly in size or disappeared after TMP-SMX therapy. The responsiveness of these MRI lesions to combination antibiotic-steroid therapy is further evidence of infectious encephalomyelitis. Histologic changes included perivascular spongiosis, cuffing of mononuclear cells in gray and white matter, and subarachnoid infiltration without neuronal degeneration. Perivascular changes were predominant in the white matter, consistent with the MRI findings.

The pathogen was not visible using routine H\&E staining. Using PAS staining, however, we observed round to oval bodies in spongiotic perivascular regions of the affected brain tissue. These bodies were also Grocott-positive. No nuclei or cell walls were recognized by histologic and ultrastructural analyses. These bodies ranged in size from 2 to $7 \mu \mathrm{m}$, larger than any known pathogenic bacterium. Some prokaryotes do not have a cell wall, including Mycoplasma among bacteria and Thermoplasma and Ignicoccus among archaea (figure 4). ${ }^{10}$ Thermoplasma tend to fuse and are therefore highly irregular in shape, similar to the pathogen observed in this study (figure e-3, amended with permission from American Society for Microbiology (C) 1995, Yasuda et $\mathrm{al}^{10}$ ).

Figure 4 Diagram of various known microbes and the present pathogen

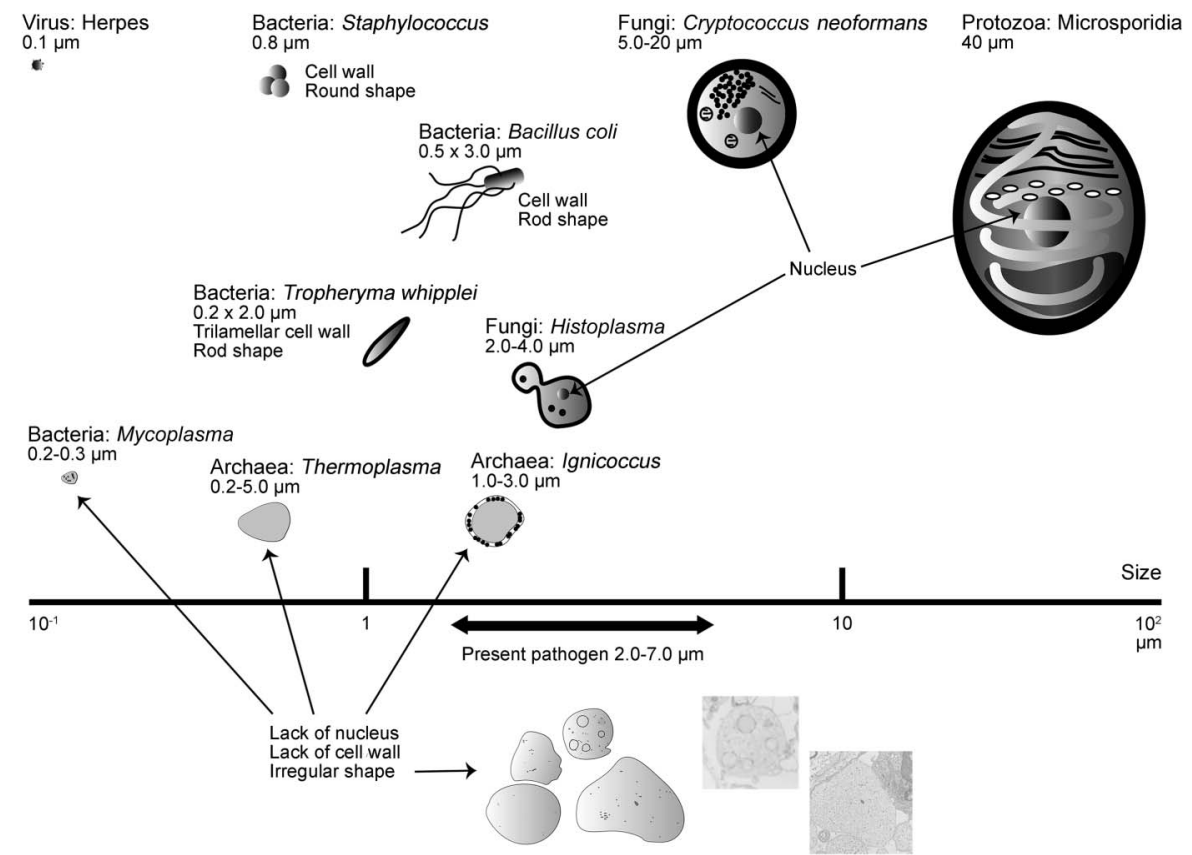

On the basis of morphologic features, the microbes could be categorized into 5 groups: virus, bacteria, fungi, protozoa, and archaea. The present pathogen is characterized by irregular shape, varying size $(2-7 \mu \mathrm{m})$, a membrane structure, and absence of both cell wall and nucleus. These morphologic features are distinguishable from those of viruses (diameter 0.02-0.3 $\mu \mathrm{m}$ ), known pathogenic bacteria (with a cell wall or differences in size), fungi (with a cell wall and nucleus), or protozoa (with a nucleus) but analogous to 2 types of archaea, Thermoplasma and Ignicoccus. 
Moreover, inhibition of cell wall synthesis by ceftriaxone induces morphologic alterations in common bacteria ${ }^{11}$; however, patients 3 and 4 were not treated with antibiotics before brain biopsy.

Unbiased high-throughput sequencing has proven effective for the identification of infectious pathogens. ${ }^{12-14}$ Using this method, we successfully identified more than 100 sequences closely homologous to the genome of Halobacterial species from the DNA samples of 2 patients (table e-3). Therefore, we propose that this unknown pathogen genetically resembles Halobacterium, a genus of the domain Archaea. Based on unique ultrastructural features and sequence homology, we suggest that the causative pathogen is a Halobacterium. Unfortunately, no amplicon products were obtained from brain tissue or CSF of patients 3 and 4 using multiple archaeal universal primers or fragment-specific primers. This may be attributed to the low amount of target pathogen DNA obtained, the high mutation rate of the archaeal genome, or the lower sensitivity of nested PCR, which can lead to false-negative results. ${ }^{15}$

No evidence of CNS disorders due to archaeal infection has been reported. The domain Archaea, one of the 3 domains of living organisms together with eukarya and bacteria, ${ }^{16}$ is a highly diverse and abundant group of prokaryotes usually inhabiting extreme environments such as salt lakes, deep seas, and hot springs. ${ }^{14}$ They have also been detected in the human vagina, colon, and oral cavity. ${ }^{17,18}$ In 2003, the pathogenicity and disease association of archaea were precisely forecasted. ${ }^{19}$ Although the virulence of these organisms has not been confirmed, the relationship between the severity of periodontal disease and the abundance of archaeal rRNA in the subgingival crevice has been reported. ${ }^{17}$

Given the abundant evidence of an infectious entity, various antibiotics, including ampicillin, ceftriaxone, streptomycin, and minocycline, were administered, none of which proved effective. In contrast, TMP-SMX plus corticosteroids had a rapid curative effect in all 4 patients. TMP-SMX monotherapy did not produce a complete therapeutic effect, suggesting that an anti-inflammatory is also required. ${ }^{9}$ We recommend a high dose of TMP-SMX (6-12 $\mathrm{g} /$ day) plus steroids as first-line treatment, as this regimen dramatically reversed symptoms in patients 1 and 3 without severe adverse events. However, patients 2 and 4 developed acute liver failure as a side effect of high-dose TMP-SMX, and neurologic symptoms gradually deteriorated upon TMP-SMX withdrawal. Patient 2 was then treated with lower-dose TMP-SMX intermittently for 5 years with substantial symptom improvement, whereas patient 4 deteriorated to a vegetative state and died despite reexposure to low-dose TMP-SMX ( $2 \mathrm{~g} /$ day $)$ in combination with corticosteroids.
We attempted to cultivate the pathogen from the biopsied brain sample of patient 3 using a medium containing $15 \%$ or $20 \% \mathrm{NaCl}$ under aerobic conditions. However, the cultivation was unsuccessful, possibly because our tissue preservation protocol may not be appropriate for organisms without cell walls, such as Mycoplasma, which are sensitive to mechanical stress. ${ }^{20}$ In this study, the target pathogen could have been destroyed by mechanical stressors such as ice crystals because all biopsied brain samples were preserved without cryoprotectants.

We propose a new disease entity for infectious encephalomyelitis identified in 4 Japanese patients on the basis of the following criteria: (1) geographical clustering; (2) comparable clinical features, including progressive dementia with involuntary tongue movements; serum and CSF cytologic examination; similar lesion patterns on MRI; and sensitivity to TMPSMX; and (3) unique ultrastructural characteristics of the undescribed pathogen. Using unbiased highthroughput sequencing, the potential pathogen was tentatively identified as a species of archaea, despite the subsequent unsuccessful genetic or cellular studies. As the next step, we need to clarify the pathogenicity of the PAS-positive agent by immunohistochemical studies using patient serum. Further experiments are required to validate archaea as the causative agent and to identify the specific species, natural host, route of transmission, pathogenic mechanism, and epidemiology. We recommend the application of high-dose TMP-SMX therapy to this encephalomyelitis. Our work will shed light on an undiagnosed encephalomyelitis.

\section{AUTHOR CONTRIBUTIONS}

Dr. Yusuke Sakiyama: acquisition of clinical data, genetic study, culture investigation, analysis and interpretation of data, and drafting the manuscript. Dr. Naoaki Kanda: study concept and design, acquisition of clinical data, and drafting the manuscript. Dr. Yujiro Higuchi: acquisition of clinical data. Dr. Michiyoshi Yoshimura: acquisition of clinical data. Dr. Hiroyuki Wakaguri: genetic study. Dr. Yoshiharu Takata: acquisition of clinical data. Dr. Osamu Watanabe: acquisition of clinical data. Dr. Junhui Yuan: genetic study. Dr. Yuichi Tashiro: acquisition of clinical data. Dr. Ryuji Saigo: acquisition of clinical data. Dr. Satoshi Nozuma: acquisition of clinical data. Ms. Akiko Yoshimura: genetic study. Ms. Shiho Arishima: pathologic study. Dr. Kenichi Ikeda: acquisition of clinical data. Dr. Kazuya Shinohara: acquisition of clinical data. Dr. Hitoshi Arata: acquisition of clinical data. Dr. Kumiko Michizono: acquisition of clinical data. Dr. Keiko Higashi: acquisition of clinical data. Dr. Akihiro Hashiguchi: acquisition of clinical data. Dr. Yuji Okamoto: genetic study. Dr. Ryuki Hirano: acquisition of clinical data. Dr. Tadafumi Shiraishi: acquisition of clinical data. Dr. Eiji Matsuura: acquisition of clinical data. Dr. Ryuichi Okubo: acquisition of clinical data. Dr. Itsuro Higuchi: acquisition of clinical data. Dr. Masamichi Goto: pathologic study. Dr. Hirofumi Hirano: acquisition of clinical data. Dr. Akira Sano: acquisition of clinical data. Dr. Takuya Iwasaki: culture investigation. Dr. Fumihiko Matsuda: genetic study. Dr. Shuji Izumo: study concept and design and pathologic study. Dr. Hiroshi Takashima: study concept and design, interpretation of the data, revising the manuscript, and study supervision. 


\section{ACKNOWLEDGMENT}

The authors thank Drs. Hirotoh Moriyama, Go Takaguchi, Shinya Tomari, Masahiro Ando, Miwa Nomura, Michihiko Goto, Daisuke Hayashi, Masahito Ichiki, and Keiichi Nakahara of Kagoshima University for their assistance with clinical examinations. The authors thank Drs. Kimiyoshi Arimura and Mitsuhiro Osame for their excellent advice. The authors also thank Professor Akihiko Yamagishi for assistance with obtaining permission to use archaeal figures (figure e-3). DNA-positive samples of bacteria, fungi, and archaea were provided from the RIKEN BioResource Center (Ibaragi, Japan). The authors thank Enago (www.enago.jp) for the English language review.

\section{STUDY FUNDING}

Dr. Takashima, Dr. Izumo, Dr. Matsuda, and Dr. Matsuura received funding through grants from the Nervous and Mental Disorders and Research Committee for Applying Health and Technology of the Ministry of Health, Welfare and Labour, Japan. Dr. Takashima and Dr. Okubo also received funding from the Ministry of Education, Culture, Sports, Science and Technology of Japan (Kiban B 25293205). Dr. Watanabe was partly supported by Health Labour Sciences Research Grants. This research is also supported by the research program for conquering intractable disease from Japan Agency for Medical Research and Development, AMED.

\section{DISCLOSURE}

Y. Sakiyama, N. Kanda, Y. Higuchi, M. Yoshimura, H. Wakaguri, Y. Takata, O. Watanabe, J. Yuan, Y. Tashiro, R. Saigo, S. Nozuma, A. Yoshimura, S. Arishima, K. Ikeda, K. Shinohara, H. Arata, K. Michizono, K. Higashi, A. Hashiguchi, Y. Okamoto, R. Hirano, T. Shiraishi, E. Matsuura, R. Okubo, I. Higuchi, M. Goto, H. Hirano, A. Sano, T. Iwasaki, and F. Matsuda report no disclosures. S. Izumo received speaker honoraria from Bayer Japan. H. Takashima received speaker honoraria from Kyushu University, GlaxoSmithKline, Bayer, Eisai, Novartis, Tanabe Mitsubishi, Biogen Idec, Benesis, Takeda, Teijin, Pfizer, and Dainippon Sumitomo Pharma and received research support from Japanese Ministry of Health, Welfare, and Labor Research Committee for Charcot-Marie-Tooth Disease, Ataxic disease, Applying Health Technology, Japan Agency for Medical Research and Development (AMED), and the Ministry of Education, Culture, Sports, Science, and Technology of Japan. Go to Neurology.org/nn for full disclosure forms.

Received December 11, 2014. Accepted in final form July 6, 2015.

\section{REFERENCES}

1. Costello DJ, Eichler FS, Grant PE, Auluck PK. Case records of the Massachusetts General Hospital. Case 1-2009. A 57-year-old man with progressive cognitive decline. $\mathrm{N}$ Engl J Med 2009;360:171-181.

2. Geschwind MD, Shu H, Haman A, Sejvar JJ, Miller BL. Rapidly progressive dementia. Ann Neurol 2008;64:97-108.

3. Yogi T, Hokama A, Kinjo F, et al. Whipple's disease: the first Japanese case diagnosed by electron microscopy and polymerase chain reaction. Intern Med 2004;43:566-570.

4. Uryu K, Sakai T, Yamamoto T, et al. Central nervous system relapse of Whipple's disease. Intern Med 2012; 51:2045-2050.
5. Yajima N, Wada R, Kimura S, et al. Whipple disease diagnosed with PCR using formalin-fixed paraffin-embedded specimens of the intestinal mucosa. Intern Med 2013;52: 219-222.

6. Yoshitake T, Kiyohara Y, Kato I, et al. Incidence and risk factors of vascular dementia and Alzheimer's disease in a defined elderly Japanese population: the Hisayama Study. Neurology 1995;45:1161-1168.

7. Chu AB, Sever JL, Madden DL, et al. Oligoclonal IgG bands in cerebrospinal fluid in various neurological diseases. Ann Neurol 1983;13:434-439.

8. Fenollar F, Puechal X, Raoult D. Whipple's disease. N Engl J Med 2007;356:55-66.

9. Schneider T, Moos V, Loddenkemper C, Marth T, Fenollar F, Raoult D. Whipple's disease: new aspects of pathogenesis and treatment. Lancet Infect Dis 2008;8: 179-190.

10. Yasuda M, Oyaizu H, Yamagishi A, Oshima T. Morphological variation of new Thermoplasma acidophilum isolates from Japanese hot springs. Appl Environ Microbiol 1995;61:3482-3485.

11. Ullmann U, Hammer-Uschtrin U. Influence of cefmenoxime, ceftriaxone, latamoxef, and ceftazidime on the lysis of Klebsiella pneumoniae: a light and electron microscopic study. Am J Med 1984;77:21-24.

12. Palacios G, Druce J, Du L, et al. A new arenavirus in a cluster of fatal transplant-associated diseases. N Engl J Med 2008;358:991-998.

13. Quail MA, Smith M, Coupland P, et al. A tale of three next generation sequencing platforms: comparison of Ion Torrent, Pacific Biosciences and Illumina MiSeq sequencers. BMC Genomics 2012;13:341.

14. Wilson MR, Naccache SN, Samayoa E, et al. Actionable diagnosis of neuroleptospirosis by next-generation sequencing. N Engl J Med 2014;370:2408-2417.

15. Kawada J, Kimura H, Ito $\mathrm{Y}$, et al. Comparison of real-time and nested PCR assays for detection of herpes simplex virus DNA. Microbiol Immunol 2004;48: 411-415.

16. Woese CR, Kandler O, Wheelis ML. Towards a natural system of organisms: proposal for the domains Archaea, Bacteria, and Eucarya. Proc Natl Acad Sci USA 1990;87: 4576-4579.

17. Lepp PW, Brinig MM, Ouverney CC, Palm K, Armitage GC, Relman DA. Methanogenic Archaea and human periodontal disease. Proc Natl Acad Sci USA 2004;101:6176-6181.

18. Dridi B. Laboratory tools for detection of archaea in humans. Clin Microbiol Infect 2012;18:825-833.

19. Eckburg PB, Lepp PW, Relman DA. Archaea and their potential role in human disease. Infect Immun 2003;71: 591-596.

20. Kim KS, Clyde WA Jr, Denny FW. Physical properties of human Mycoplasma species. J Bacteriol 1966;92: 214-219. 


\section{Neurology ${ }^{\oplus}$ \\ Neuroimmunology \& Neuroinflammation}

New type of encephalomyelitis responsive to trimethoprim/sulfamethoxazole treatment in Japan

Yusuke Sakiyama, Naoaki Kanda, Yujiro Higuchi, et al.

Neurol Neuroimmunol Neuroinflamm 2015;2;

DOI 10.1212/NXI.0000000000000143

This information is current as of August 13, 2015

Neurol Neuroimmunol Neuroinflamm is an official journal of the American Academy of Neurology.

Published since April 2014, it is an open-access, online-only, continuous publication journal. Copyright $($ ) 2015 American Academy of Neurology. All rights reserved. Online ISSN: 2332-7812.

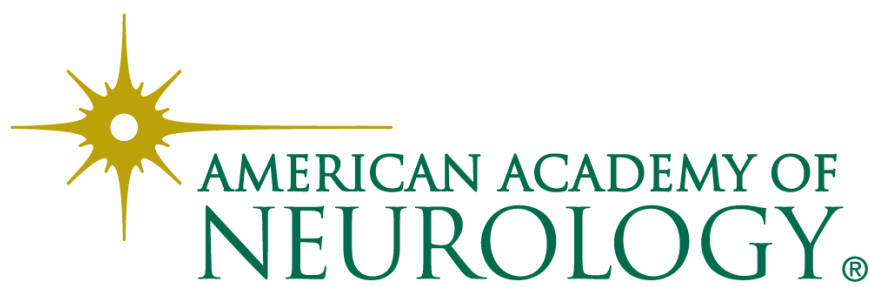




\section{Updated Information \&} Services

\section{Supplementary Material}

References

Subspecialty Collections

Permissions \& Licensing

Reprints including high resolution figures, can be found at: http://nn.neurology.org/content/2/5/e143.full.html

Supplementary material can be found at: http://nn.neurology.org/content/suppl/2015/08/13/2.5.e143.DC1

This article cites 20 articles, 5 of which you can access for free at: http://nn.neurology.org/content/2/5/e143.full.html\#\#ref-list-1

This article, along with others on similar topics, appears in the following collection(s):

All Clinical Neurology

http://nn.neurology.org//cgi/collection/all_clinical_neurology All Cognitive Disorders/Dementia http://nn.neurology.org//cgi/collection/all_cognitive_disorders_dementi a

All Genetics

http://nn.neurology.org//cgi/collection/all_genetics

Encephalitis

http://nn.neurology.org//cgi/collection/encephalitis

Spinal cord infection

http://nn.neurology.org//cgi/collection/spinal_cord_infection

Information about reproducing this article in parts (figures,tables) or in its entirety can be found online at:

http://nn.neurology.org/misc/about.xhtml\#permissions

Information about ordering reprints can be found online: http://nn.neurology.org/misc/addir.xhtml\#reprintsus

Neurol Neuroimmunol Neuroinflamm is an official journal of the American Academy of Neurology.

Published since April 2014, it is an open-access, online-only, continuous publication journal. Copyright $\odot$ 2015 American Academy of Neurology. All rights reserved. Online ISSN: 2332-7812.

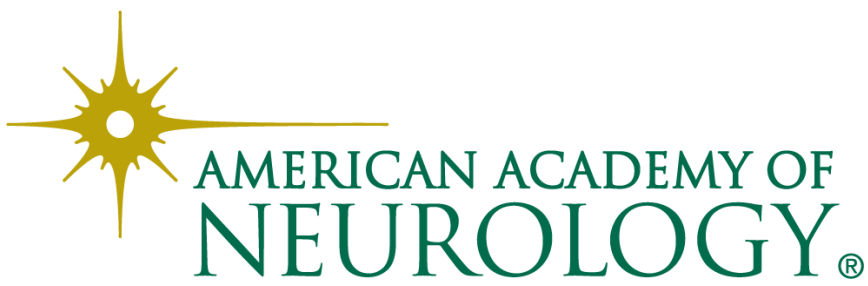

